\title{
A PROPÓSITO DAS RELAÇÕES ENTRE ETNICIDADE, CULTURA, PODER E SAÚDE
}

\author{
Mara Viveros Vigoya
}

\section{Introdução}

Antes de começar a fazer meu comentário sobre o artigo Etnia, raça e saúde sob uma perspectiva nominalista, de José Carlos dos Anjos, quero compartilhar com vocês a dificuldade que implicou para mim a realização deste exercício. A proximidade lingüística entre o português e o espanhol preparou-me mais de uma armadilha, e estive constantemente exposta a dois riscos: trair o texto, por minha tradução livre, e/ou traí-lo pela interpretação dos propósitos densos - e intelectualmente sofisticados - do autor. Espero ter me saído bem no exercício e não empobrecer os horizontes que esse autor nos abre com suas reflexões.

O trabalho de J. C. dos Anjos é interessante e necessário, porque permite relacionar uma perspectiva histórica e uma perspectiva socioantropológica da saúde, as categorias de raça, etnia e seus vínculos, na nova problemática da etnicidade na saúde (principalmente sexual e reprodutiva). Em primeiro lugar, o autor situa historicamente a categoria da raça, como um correlato do processo de propagação de uma biorracionalização do governo e da difusão de tecnologias locais de poder, para administrar a população, cujos objetivos foram a constituição de um corpo saudável e homogêneo de nação e o treinamento e a maximização das forças produtivas. Em segundo lugar, ele discute alguns enfoques antropológicos sobre as diferenças culturais. Em particular, detém-se na análise da defasagem existente entre as representações locais do corpo e da saúde e as imagens projetadas pelos órgãos e documentos oficiais que trabalham com a questão da saúde em situações multiétnicas. Em terceiro lugar, ele apresenta a convergência dessas duas perspectivas, numa discussão sobre a dominação e as possibilidades presentes no diálogo interétnico, quando o que está em jogo são as políticas públicas de saúde. 
Neste texto, farei referência, em primeiro lugar, à relação entre a saúde e o biopoder, bem como entre o biopoder, a saúde e a raça, para terminar com uma reflexão sobre a saúde e a cultura, ilustrada, particularmente, pela leitura culturalista da epidemia de Aids na África. A referência a esse caso me servirá para introduzir alguns comentários gerais sobre os imaginários racistas e seus efeitos sociais. Em segundo lugar, exploro algumas das dificuldades do tema das resistências étnico-raciais, para culminar numa reflexão sobre as interrogações abertas pela perspectiva foucaultiana da hermenêutica do sujeito na análise das políticas de saúde.

\section{O campo da saúde e o biopoder}

José Carlos dos Anjos mostra de que forma o campo sanitário foi e continua a ser um lugar de interpretação do mundo e de enunciação do discurso político. Na verdade, essa assunção das questões sanitárias por parte das instituições sociais e políticas não é nova e, hoje em dia, a aplicação do político ao biológico continua a ocupar um lugar central no espaço público. $\mathrm{O}$ autor sublinha a importância do conceito de biopoder na discussão sobre a pertinência das categorias de raça e etnia. Na obra de Foucault, o biopoder é definido como a conjunção de uma anatomopolítica e uma biopolítica. A primeira representa o controle do corpo como máquina por tecnologias que, tal como a escola, o cárcere e a medicina, intervêm em suas atitudes e as disciplinam. A segunda, a biopolítica, faz referência a uma imposição sobre o que é designado como corpo-espécie, através de dispositivos que regulam sua natalidade, fecundidade e morbidez, incluindo sua morte e sua mortalidade, quer em termos de conhecimento, graças à demografia ou à epidemiologia, quer em termos de ação, como no planejamento familiar e na saúde pública.

O biopoder é considerado por Michel Foucault como um processo de normalização que define uma ordem moral e política, e o discurso sobre o sexo, tal como descrito no primeiro volume de História da Sexualidade, constituiria a ilustração paradigmática dessa conjunção entre anatomopolítica e biopolítica. Mas também o discurso sobre a raça, em sua acepção moderna, ou seja, o discurso que enfatiza a pureza biológica do povo de uma nação, pressupõe, como assinala Anjos, o exercício de um biopoder, já que este gera segregação e hierarquização social, relações de dominação e efeitos de hegemonia (Foucault, 1976). Só se pode falar de raça, em sua acepção estatal e biologizante, quando a saúde das populações emerge como uma questão social na esfera pública, e quando os fenômenos próprios da vida da espécie humana entram 
na ordem do poder e no campo das técnicas políticas. Desde a segunda metade do século XIX, as políticas populacionais, da família e da hierarquização social, assim como as intervenções sobre o corpo, a saúde e as condutas da vida cotidiana, encontraram justificativa na preocupação com a proteção da pureza do sangue e com o futuro da espécie. Essa ordenação eugênica da sociedade implicou a faculdade de fazer com que uns vivam, a fim de rechaçar outros para a morte e de, nesse sentido, estabelecer dispositivos de genocídio sistemático daqueles que são designados no lugar de 'outros'.

\section{O biopoder, a saúde e a raça}

José Carlos dos Anjos afirma que a reflexão a respeito desse biopoder é necessária na discussão sobre a pertinência das categorias de raça e etnia para a análise da formação social brasileira. No Brasil, como na Colômbia, as elites do fim do século XIX e início do século XX apropriaram-se, simultaneamente, do discurso racial surgido na Europa durante o século XIX e dos dispositivos de biopoder. Essas minorias seletas pretenderam construir uma nação segundo o modelo das nações modernas e ocidentais, buscando seus princípios de racionalidade e modernidade na herança européia e outorgando à herança africana um lugar na sociedade e na cultura unicamente como fonte de "poder físico, folclórico e culinária rica" (Sombra Saravia, 1993:45). O Brasil favoreceu o embranquecimento de sua sociedade através do amplo incentivo à imigração européia, que modificou, em grande medida, a composição racial brasileira. $\mathrm{O}$ correlato desse incentivo, para Anjos, foi a invisibilização das populações nacionais para políticas públicas como as de saúde. Por essa razão, para esse autor, a forma adotada pela produção das raças no Brasil não está dissociada do modo como foram construídas as políticas sanitárias.

A medicalização e a normalização crescentes da vida individual e coletiva, trazidas pela era do biopoder, foram ainda mais explícitas nos contextos interétnicos latino-americanos, nos quais as especificidades culturais das populações foram ignoradas. A cultura da saúde pública implicou uma vasta empreitada de aculturação das populações indígenas e africanas, através de dispositivos de imposição e persuasão que traziam implícita a chancela de uma missão civilizadora. Do mesmo modo, a implementação de programas de combate às grandes endemias esteve e continua sempre associada a práticas de inferiorização e submissão dessas populações, isto é, à constituição de relações políticas específicas, nas quais a sociedade ocidental tem exercido seu poder através da imposição de seus saberes médicos e de seus controles sanitários (Fassin, 2001). 


\section{A saúde e a cultura}

Parece pertinente fazer uma reflexão sobre a relação entre saúde e cultura, para dar conta das tensões entre universalismo e particularismo - ou culturalismo - que sempre atravessaram o campo da saúde pública, e que ressurgem quando se problematiza a relação entre etnicidade e saúde. Recorreremos ao exemplo da luta contra a Aids, porque ela vem a ser um revelador privilegiado das ambigüidades e contradições das políticas que oscilam entre a aplicação de princípios universais e a busca de particularidades culturais, incessantemente invocadas para explicar as dificuldades encontradas nessa iniciativa.

Essa tensão é constitutiva da história da saúde pública no mundo colonial e, posteriormente, no que veio a ser chamado de Terceiro Mundo. Em nenhum momento, um ou outro enfoque conseguiu impor-se totalmente, como solução prática e definitiva para os problemas de saúde das sociedades asiáticas, africanas ou latino-americanas. O trabalho de antropólogos como Didier Fassin e Jean Pierre Dozon, na América Latina e na África, mostra que essas duas perspectivas reúnem-se tanto no plano da interpretação, através da denegação dos aspectos políticos subjacentes nas opções de saúde pública, quanto no da ação, por sua incapacidade de reconhecer a existência e menos ainda a pertinência das soluções elaboradas pelos próprios agentes de saúde locais.

Tornando-se invisível como cultura, a saúde pública produziu o 'outro' como categoria culturalmente definida (Fassin, 2001). A superação dessa aporia pressuporia o rompimento, como afirmam esses dois autores, com a idéia de que a saúde pública é um saber que enuncia verdades sobre o bom comportamento para a vida e se confronta com culturas ignorantes ou desrespeitadoras dessas verdades, a fim de dar margem a uma outra concepção da relação entre saúde pública e cultura, considerada como uma interação entre códigos culturais que formulam verdades referentes a teorias locais.

É necessário considerar que a suposta distância existente entre as normas sanitárias prescritas e as representações e práticas em matéria de higiene, sexualidade e cuidados de saúde não depende unicamente das diferenças ligadas à origem geográfica, mas também das desigualdades sociais. As argumentações culturalistas em curso, expressão de uma ideologia particularista para pensar sobre o 'outro' levam a minimizar e até a ocultar o papel das condições materiais nas condutas consideradas nocivas, bem como a responsabilidade das instituições de saúde nas dificuldades encontradas para implementar as ações sanitárias (Dozon \& Fassin, 2001). A Aids é um revelador particularmente eficaz dessa ocultação. Na história da epidemia desta doença, a África foi rapidamente designada como berço e vetor da epidemia, e ressurgiram com vi- 
gor diversas representações exóticas e estigmatizantes da Aids africana, assim como, vez por outra, imagens etnicizantes e racistas.

Num artigo recente, Jean Pierre Dozon (2001) afirma que a leitura culturalista da epidemia na África, tanto nos trabalhos científicos quanto em seus ecos na mídia e suas conseqüências políticas, teve como efeito a orientação exclusiva das campanhas de prevenção para o uso do preservativo, deixando de lado outras formas de transmissão do vírus e elementos socioeconômicos como a pobreza, a violência e a carência ou má qualidade dos serviços de saúde, que tanto reforçam a ocorrência da infecção quanto a gravidade da doença.

A Aids tem sido acompanhada por múltiplas construções da 'alteridade'. Em seus primórdios, foi chamada de 'câncer gay' e, posteriormente, converteuse numa moléstia transmissível pelo sexo ou pelo sangue, mas que afetaria particularmente certas populações, como os homossexuais, os heroinômanos, os haitianos e os hemofílicos, que foram chamados de 'os quatro agás'. No mundo de hoje, a expansão planetária da Aids gerou uma imagem maior da 'alteridade' encarnada pela África subsaariana, percebida como um 'grupo de risco' de grandes dimensões, ou como um universo de grande vulnerabilidade. Existe uma visão global que representa essa região como um mundo à parte, no qual nada acontece da mesma maneira que noutros lugares. Os argumentos epidemiológicos associam-se, muito espontaneamente, a uma doxa culturalista, que constrói o modelo de uma cultura sexual negra, específica e irredutível, caracterizada pela lassidão e pela promiscuidade.

A explicação cultural da Aids implicou, em algumas ocasiões, a classificação de certos traços culturais e certos costumes, a exemplo da poliginia, do levirato ou do sororato, como fatores favorecedores da disseminação rápida do HIV, ao passo que outros hábitos associados ao rigor muçulmano, como as proibições sexuais pós-parto ou a circuncisão, são percebidos como fatores de refreamento. Por parte das próprias populações, deram-se explicações culturais da Aids que a interpretam como conseqüência da debilitação dos costumes ancestrais pelo mundo moderno, e não como uma calamidade produzida pela propensão 'absurda' a perpetuá-los, como tende a ser afirmado atualmente (Fay, 1999, citado em Dozon, 2001).

$\mathrm{Na}$ totalidade dos casos, a ênfase tem sido depositada no problema de uma cultura sexual ou uma forma de vida próprias da África, e os programas nacionais de combate à Aids consideraram tão importante efetuar uma certa moralização dos costumes quanto difundir a utilização de meios de prevenção, como o preservativo. Os fatores econômicos e sociopolíticos foram deixados fora da análise e das propostas de intervenção, como se não fossem constitutivos das situações de risco. Dozon insiste em assinalar aspectos que incidem na 
propagação do HIV, como, por exemplo, os deslocamentos humanos, que hoje se produzem não apenas pelos movimentos internos do êxodo rural e da urbanização, mas também pelos movimentos transnacionais da população, ainda causados por razões econômicas, bem como políticas. Esse autor indica o peso que têm atualmente as múltiplas expressões de violência interna nos países africanos, manifestações estas que vêm prolongando processos de autoritarismo e repressão característicos da situação colonial e pós-colonial na África.

\section{Os efeitos sociais dos imaginários racistas e as possibilidades de resistência}

As reflexões de Dozon levam-me a comentar outro trecho do texto de J. C. dos Anjos, no qual é afirmado que a dominação étnica coloca as etnias dominadas na posição de objetos (de prazer, de políticas e controles higienistas, de acusação de uma sexualidade não-domesticada), mas também de objetos de admiração e de mediações que os despojam de seu lugar como sujeitos, o que torna necessária a presença de porta-vozes no espaço público. A racialização das populações cria o espaço para se estabelecer correlações entre uma sexualidade 'natural' (um erotismo selvagem) e uma vulnerabilidade maior da saúde e da saúde reprodutiva. Esta última converte-se, como assinala o autor - seguindo a perspectiva analítica de Bourdieu (1980) —, numa típica profecia auto-realizadora, sob os efeitos conjuntos de condições objetivas de exclusão e da incorporação subjetiva do estigma de que essas populações têm sido portadoras. As populações são racializadas por meio da naturalização de uma sexualidade que as torna vulneráveis às doenças sexualmente transmissíveis, ou seja, por um processo de somatização cujo término poderia ser a eliminação daqueles que são colocados no lugar de raça inferior.

Parece-me importante deter-me por um momento no processo de naturalização da sexualidade das etnias dominadas e, em particular, na associação das populações negras com uma sexualidade indomada (Viveros, 2000). A partir de uma perspectiva sociohistórica, a vinculação do negro com uma sexualidade desenfreada pode ser analisada como um dos vestígios da escravidão que permanece presente nos imaginários sociais. O crítico literário Victorien Lavou-Zoungbo (2001) afirma que o mito das proezas sexuais do negro é o corolário do mito de seu vigor e força físicos, e constitui um meta-relato, ou seja, é uma narrativa que desempenha uma função legitimadora. Com efeito, os imaginários construídos sobre o negro cumpriram e continuam a cumprir o objetivo de legitimar os próprios fatos da colonização e da escravidão, seu espírito 
'civilizador'. Qual é a razão por que certas visões do 'outro' - neste caso, do negro como um ser dionisíaco (Viveros, 2000) e vigoroso - permanecem e se reproduzem?

Segundo esse autor, uma das razões que explica a persistência desse meta-relato na memória coletiva ocidental-americana é sua difusão e renovação constantes em cenários distintos: o festivo, como, por exemplo, o dos carnavais brasileiros; o desportivo, através da reativação nos imaginários ocidentais, do mito do garanhão negro, encarnado pelos atletas negros; ou o âmbito dos discursos da saúde pública, nos quais se associa constantemente a epidemia de Aids ao continente africano, como vimos anteriormente. $\mathrm{O}$ mesmo acontece na literatura, no discurso publicitário ou nas mensagens difundidas através da Internet, que atribuem um lugar privilegiado aos temas eróticos 'negros'. Outra possível explicação para a permanência dessa representação está no fato de que ela é compartilhada por negros e não-negros, ainda que, evidentemente, a partir de posições diferentes de enunciação (Viveros, 2000).

É importante assinalar que o meta-relato da proeza-virilidade dos negros não é isento de conseqüências. Em primeiro lugar, ele se constitui como a fronteira, o umbral (anatômico, biológico, ontológico ou imaginário) a partir do qual se constrói e se justifica a humanidade exclusiva ocidental-européia'branca' (Lavou-Zoungbo, 2001). Outro de seus efeitos é que ele identifica o negro com a natureza, e não com a cultura, e lhe atribui a mesma ambivalência: ora ele é percebido como passivo e dependente, como uma criança, e é descrito como carente (de iniciativa, de capacidade intelectual, de vontade), ora é exagerado (em emotividade, irracionalidade ou sexualidade). Em terceiro lugar, ele encerra o negro nesse estereótipo, 'fixa-o' em seu sexo. Para o imaginário ocidental, o sexo transformou-se num dos traços pertinentes para a definição do ser negro. Em quarto lugar, ele faz com que toda forma de sexualidade que implique um homem ou uma mulher negros torne-se suspeita de lascívia e sensualidade exageradas. Em quinto lugar, torna as populações negras particularmente vulneráveis às doenças sexualmente transmissíveis, como nos recorda Anjos. O meta-relato de proeza-vigor sexual mais faz condenar e desqualificar o negro do que exaltá-lo. E, diferentemente de outros meta-relatos, a primeira vítima deste é seu protagonista (Lavou-Zoungbo, 2001).

Uma das perguntas surgidas a partir dessas constatações concerne às formas de resistência que podem ser oferecidas pelas populações negras. $\mathrm{O}$ artigo de Anjos afirma, seguindo Bourdieu (1980), que os dominados têm menos capacidade de realizar uma revolução simbólica do que os dominadores. E essa revolução constitui uma condição para a reapropriação da identidade social de que os negros foram expropriados (inclusive subjetivamente), ao aceitarem 
as taxonomias dominantes. Entretanto, essa suposta incapacidade dos dominados de resistir aos relatos produzidos sobre eles pelos grupos dominantes gera em mim alguns comentários e interrogações. Um deles tem a ver com a possibilidade e o alcance da estratégia que os grupos dominados podem adotar, ao se apropriarem do estigma que pesa sobre eles e lhe darem uma nova significação, convertendo-o num atributo positivo. De que lugar de enunciação poderia ser feita essa ressignificação? Uma resposta provável é que ela poderia ser feita a partir de um questionamento da ordem moral ocidental, que tem conferido ao sexo um lugar problemático e ameaçador. Mas isso suporia um trabalho não só a propósito dos imaginários racistas, mas também sobre os imaginários e as práticas do gênero sexual que respaldam esse relato da proeza sexual dos negros.

Se admitirmos que esse mito do negro como um bicho físico e sexual o estereotipa numa espécie de alteridade radical, absoluta, que o condena e desqualifica, desmontar esse relato passa a ser uma tarefa que se torna urgente para a recuperação de sua identidade social. Para tanto, faz-se necessário explicitar os subentendidos e as dinâmicas subjacentes a ele, sublinhando os infortúnios a que tal relato deu lugar (Lavou-Zoungbo, 2001). Mas isso também implica trabalhar, a partir das expressões distintas do movimento negro, em prol da aceitação, da reivindicação e da apropriação da presença, da história e da identidade dos negros na América Latina, não como um componente alicerçado nas lembranças, na herança e no ritualismo, mas como elementos atuantes e atuais das identidades nacionais latino-americanas, com toda a sua diversidade, complexidade e dinamismo.

\section{As resistências étnico-raciais e os espaços de mediação}

José Carlos dos Anjos identifica outro ponto problemático, relacionado com as resistências étnico-raciais: o das mediações políticas e dos porta-vozes legítimos, reconhecidos ou não, das etnias dominadas. $\mathrm{O}$ autor assinala que a censura imposta às etnias dominadas, para que elas não ocupem o espaço público, permite a constituição de âmbitos de especialistas nas mediaçōes políticas. Com efeito, ao se converter num assunto debatido no espaço público, o problema da raça, etnia e saúde gera um lugar de concorrência pela mediação, no qual os agentes participantes oferecem as especificidades de seus saberes profissionais e outros capitais acumulados em suas trajetórias político-culturais, para sustentar sua condição de porta-vozes legítimos das populações que são objeto da racialização. 
O autor compara o processo de problematização das condições de vulnerabilidade das raças dominadas frente às doenças sexualmente transmissíveis, em particular frente à Aids, com esse mesmo processo no caso dos homossexuais, e tira algumas conclusões que merecem certos comentários. Em relação aos homossexuais, uma das condições de êxito na consolidação desse tema na agenda política tem a ver, segundo esse autor, com o processo de institucionalização dessa identidade específica como lugar de enunciação. Os maiores dividendos da problemática Aids/homossexuais foram obtidos a partir de sua incorporação por grandes organizações não-governamentais, que estavam aptas a negociar os interesses particulares da comunidade homossexual sem perder de vista a dimensão universalista da problemática social da epidemia.

No caso da problemática etnia-raça/saúde, o processo foi diferente, porque esse espaço de mediação política foi ocupado não só por militantes do movimento negro, mas também por pessoas cujo discurso provém de lugares de enunciação 'alheios' às identidades do grupo estigmatizado (como é o caso dos antropólogos ${ }^{1}$ e dos agentes do Estado, apesar de eles se perceberem como porta-vozes autorizados dos que são despojados da palavra no âmbito público). As posições, os recursos, as trajetórias e as retóricas desses agentes distintos são muito díspares entre si, gerando constantemente, nesses espaços, conflitos que mais devem ser conceituados, segundo Anjos, em termos de dominação racial e de imposição do poder (por parte dos que possuem maior capital cultural ou político) do que de atritos interétnicos.

Segundo esse autor, para os líderes do movimento negro - cuja legitimidade como porta-vozes constrói-se a partir de suas narrativas biográficas e de suas posições antiintelectualistas - , tem sido difícil acumular o capital político e cultural suficiente e necessário para construir um discurso que parta de uma visão global, como conseguiram fazer os agentes homossexuais provenientes de identidades e atividades locais. O autor conclui que não há razões objetivas para esperar que as condições de interlocução no interior dessas "comunidades de comunicação interétnicas" se adaptem aos requisitos do ideal de uma comunidade de argumentação eticamente constituída.

Todavia, partindo de meu desconhecimento da realidade brasileira e das reflexões que se fizeram na Colômbia sobre a configuração da questão

1 J. C. dos Anjos utiliza a categoria dos antropólogos como se esta designasse um conjunto homogêneo de investigadores, desconhecendo os debates que se deram no interior da disciplina sobre a relação e as tensões entre conhecimento e política. 
étnica para as comunidades negras, me surgem outras perguntas. Uma delas é sobre a influência que as formas pelas quais as identidades foram entendidas, a partir do movimento negro, podem exercer em sua formação como atores políticos e em seu poder como interlocutores das políticas públicas. Conquanto, para muitos, a identidade tenha sido entendida como algo enraizado numa série de práticas, concebidas como essenciais e ancestrais - como seria o caso dos remanescentes dos quilombos, no Brasil, ou das comunidades negras do Pacífico, na Colômbia - para outros, a identidade foi interpretada como um projeto em construção. A pessoa 'torna-se' negra mediante um processo de posicionamento político-cultural na prática (Hall, 1999).

Essas tendências manifestam um desejo de construir uma identidade negra fora das imagens construídas pelos grupos sociais dominantes, e expressam o anseio de passar de uma forma de identidade de resistência para uma identidade de projeto, de acordo com os termos de Castells (1997). Segundo esse autor, a primeira seria uma identidade gerada pelos atores que se encontram em posições desvalorizadas ou estigmatizadas pela lógica da dominação, razão pela qual eles constroem espaços de resistência e sobrevivência baseados em princípios diferentes dos propostos pelas instituições dominantes. A segunda, a identidade de projeto, seria aquela em que os atores sociais, dado o material cultural estabelecido de que dispõem, procurariam construir uma nova identidade, capaz de redefinir sua posição na sociedade e, com isso, transformar toda a estrutura social.

\section{Da genealogia do poder à hermenêutica do sujeito}

Para terminar, eu gostaria de voltar às colocações iniciais de José Carlos dos Anjos, quando ele calcou sua reflexão sobre a saúde e a raça numa perspectiva foucaultiana do biopoder. Vou fazê-lo trazendo para o cotejo a sugestiva exposição de Didier Fassin (1999) a propósito dos enfoques foucaultianos sobre medicina, saúde e doença. Diz Fassin que a maioria dos estudos realizados sobre essa problemática, nas ciências sociais, referiu-se à questão do nascimento da clínica, o que corresponderia à primeira fase do trabalho de Foucault (1963), ou seja, a sua fase 'arqueológica', orientada para o estudo da construção do olhar médico sobre o corpo.

Outra série de trabalhos históricos, antropológicos e sociológicos entre os quais poderíamos situar o de Anjos - foi feita sobre políticas de saúde e utilizou o conceito de biopoder, desenvolvido na segunda fase do trabalho de Foucault (1976), a fase genealógica, para denunciar o controle crescen- 
te da sociedade e, em especial, do Estado, através do disciplinamento dos corpos e da regulação da população. A tese de Fassin diz que, para entender o que ocorre hoje no campo da saúde, além da aplicação do político ao biológico, é preciso abordar a questão a partir dos processos de subjetivação - terceira fase, ou fase hermenêutica - através dos quais o mundo social é representado e as desigualdades sociais se mostram de modo caricato (na medida em que é um modo psicologizante). Minha pergunta é se esse espaço conceitual, que foi muito pouco explorado, poderia ser fecundo para a compreensão da relação entre etnicidade e saúde.

Uma das transformações culturais mais importantes de nossa época, em particular na sociedade ocidental, é a passagem de uma visão de saúde pública que enfatiza a luta para diminuir as desigualdades sociais relacionadas com a saúde para uma política social que incorpora tanto o sofrimento psíquico (isto é, a experiência subjetiva da doença) quanto uma visão do indivíduo como ser sofredor. Esse deslocamento ocorre simultaneamente e como conseqüência de uma nova representação do espaço social, como uma sociedade que já não se organiza vertical e hierarquicamente, mas se estrutura horizontalmente, com um interior composto pelos integrados e um exterior que reúne os excluídos (os deficientes, os velhos, os desabrigados, os doentes de Aids etc.). Essa exclusão contemporânea se caracterizaria por dois traços: a vitimação e a singularização. A vitimação seria acompanhada por uma reprovação das vítimas como irresponsáveis, enquanto a singularização faz referência às características do individualismo negativo - perda dos vínculos antes gerados pela inserção no trabalho, impossibilidade de construir um projeto de vida - descritas por Robert Castel (1995) em seu livro As Metamorfoses da Questão Social: uma crônica do assalariado.

Poderíamos dizer que assistimos hoje a uma era em que o biopoder começa a se caracterizar mais por sua impotência do que por seu excesso de controle, um período em que a margem de ação dos agentes locais é muito reduzida e em que o nível de frustração gerado pelas novas situações sociais é muito alto (Bourdieu, 1993). É importante deixar claro, no entanto, que essa mudança é uma transformação mais gradativa do que radical e que, atualmente, essas duas maneiras de conceber as desigualdades sociais e as políticas sociais coexistem. Embora esse processo seja mais evidente na Europa e nos Estados Unidos, as sociedades latino-americanas não estão alheias a ele e, do mesmo modo que se pode falar de uma globalização da economia, poder-se-ia falar de uma globalização da subjetividade.

Um dos sintomas dessa mudança é o papel hoje desempenhado pelas formas de ajuda humanitária no campo da saúde. Talvez seja necessário lem- 
brar que a realidade global da subjetivação das desigualdades sociais é sempre diferenciada, e que o sofrimento dos diferentes setores sociais não é percebido da mesma maneira pela sociedade nem ocupa o mesmo lugar no espaço público. Isso significa que a vida das pessoas de um mesmo país não tem a mesma existência social e que, por esse ponto de vista, a vida dos membros dos grupos sociais dominados - e, no caso que nos interessa, das etnias dominadas não dá margem ao mesmo tratamento que teria a vida de um membro dos grupos sociais ou etnias dominantes.

Para dizê-lo de outra maneira, é como se existissem escalas de valores diferentes para medir a humanidade das vidas (Fassin, 2001), escalas estas que têm como resultado o genocídio oculto de que falamos no início deste texto. Essas novas realidades certamente trazem consequiências para os estudos realizados pelas ciências sobre a saúde e as políticas públicas de saúde. Uma reflexão sobre a relação entre a etnicidade e a saúde no mundo contemporâneo também deve levar em conta os processos de subjetivação das desigualdades sociais sanitárias das etnias dominadas, o que sustenta e dá sentido às políticas de saúde com que se responde a essas desigualdades.

Tradução de Vera Ribeiro. 


\section{Referências bibliográficas}

BOURDIEU, P. Le Sens Pratique. Paris: Éditions de Minuit, 1980.

BOURDIEU, P. La Misère du Monde. Paris: Éditions du Seuil, 1993.

CASTEL, R. Les Métamorphoses de la Question Sociale: une chronique du salariat. Paris: Fayard, 1995.

CASTELLS, M. Le Pouvoir de l'Identité. Paris: Fayard Éditions, 1997.

DOZON, J. P. Le Sida et l'Afrique ou la causalité culturelle en question. In: DOZON, J. P. \& FASSIN, D. (Orgs.) Une Critique de la Santé Publique: une approche anthropologique, Paris: Balland, 2001.

DOZON, J. P. \& FASSIN, D. (Orgs.) Une Critique de la Santé Publique: une approche anthropologique. Paris: Balland, 2001.

FASSIN, D. La patetización del mundo. Ensayo de antropología política del sufrimiento. In: VIVEROS, M. \& GARAY, G. (Orgs.) Cuerpo, Diferencias y Desigualdades. Bogotá: CES/Universidad Nacional de Colombia, 1999.

FASSIN, D. Au coeur de la cité salubre: la santé publique entre les mots et les choses. In: DOZON, J. P. \& FASSIN, D. (Orgs.) Une Critique de la Santé Publique: une approche anthropologique. Paris: Balland, 2001.

FAY, C. Du culturel, de l'universel ou du social. Penser le Sida et la prévention au Mali. In: BECKER, C. et al. (Orgs.) Vivre et Penser le Sida en Afrique. Paris: Codesria-Karthala-IRD, 1999.

FOUCAULT, M. Naissance de la Clinique: une archéologie du regard medical. Paris: Presses Universitaires de France, 1963.

FOUCAULT, M. Histoire de la Sexualité. I. La volonté de savoir, Paris: Gallimard, 1976.

[História da Sexualidade. I. A vontade de saber, 6. ed. Rio de Janeiro: Graal, 1985].

HALL, S. Identidad cultural y diáspora. In: CASTRO-GÓMEZ, S.; GUARDIOLARIVERA, O. \& MILLÁN DE BENAVIDES, C. (Orgs.) Pensar (en) los Intersticios: teoría y práctica de la crítica postcolonial. Bogotá: Colección Pensar, 1999.

LAVOU-ZOUNGBO, V. Du nègre comme un hercule doublé d'un Saint-Phallus: une humanité différée. Marges, 21:59-93, 2001.

SOMBRA SARAVIA, J. F. Silencio y ambivalencia: el mundo de los negros en Brasil. América Negra, 6:37-53, 1993.

VIVEROS VIGOYA, M. Dionisios negros: corporalidad, sexualidad y orden socioracial en Colombia. In: FIGUEROA MUÑOZ, B. \& SANMIGUEL, P. (Orgs.) ¿Mestizo yo? Bogotá: CES/Universidad Nacional, 2000. 